\title{
O "YATAY POÑI" DE AIMÉ BONPLAND: ETIMOLOGIA E NOTA TAXONÔMICA ${ }^{1}$
}

\author{
JOSÉ NEWTON CARDOSO MARCHIORI²
}

\section{RESUMO}

Embora reconhecido por Aimé Bonpland como espécie distinta desde meados do século dezenove, o "yatay poñi" do botânico francês foi descrito apenas recentemente, sob o nome de Butia Noblickii Deble, Marchiori, F.S. Alves \& A.S. de Oliveira. No presente trabalho é analisada a etimologia do nome comum e comprovado que essa espécie é botanicamente distinta de Butia poni (Hauman) Burret.

Palavras-chave: Aimé Bonpland, Arecaceae, Butiá de Bonpland, Butia Noblickii, Butia poni, Butia yatay, Cocos poni, Yatay poñi.

\section{ABSTRACT}

[The "yatay poñi" of Aimé Bonpland: etimology and taxonomic note].

Although recognized by Aimé Bonpland as a distinct species since de mid-nineteenth century, the "yatay poñi" of the French botanist was described only recently under the name Butia Noblickii Deble, Marchiori, F.S. Alves \& A.S. de Oliveira. The etimology of the common name is examined in this paper, been demonstrated that the species is botanically distinct with respect to Butia poni (Hauman) Burret.

Key words: Aimé Bonpland, Arecaceae, Bonpland's palm tree, Butia Noblickii, Butia poni, Butia yatay, Cocos poni, Yatay poñi.

\section{INTRODUÇÃO}

Embora descrita recentemente, Butia Noblickii Deble, Marchiori, F.S. Alves \& A.S. Oliveira já era reconhecida por Aimé Bonpland como espécie distinta do verdadeiro "yatay" (Butia yatay (Mart.) Becc.) desde março de 1854, pelo menos, conforme registro do botânico francês em seu "Journal de Botanique", obra cujo segundo volume veio a lume em 1924, sob o título de "Archives Inédites". 3

No presente artigo é analisada a etimologia do termo "yatay poñi", utilizado por Bonpland, bem como a introdução deste epíteto vulgar na literatura taxonômica, mediante latinização,

1 Recebido em 05-12-2014 e aceito em 25-03-2015.

2 Engenheiro Florestal, Dr. Bolsista de Produtividade em Pesquisa (CNPq - Brasil). Professor Titular, Departamento de Ciências Florestais, Universidade Federal de Santa Maria.marchiori@pq.cnpq.br

3 Esta comprovação foi objeto de publicação no seguinte artigo desta mesma revista: MARCHIORI, J.N.C. Resgate histórico para o butiá de Bonpland, Butia Noblickii Deble, Marchiori, F.S. Alves \& A.S Oliveira, Arecaceae da província de Corrientes, Argentina. Balduinia, Santa Maria, n. 47, p. 1-11, 2015. aplicado a uma espécie de palmeira anã muito distinta de Butia Noblickii.

\section{CONSIDERAÇÕES ETIMOLÓGICAS}

Não restam dúvidas sobre a origem dos termos "yatay" e "poñi", atribuídos por Aimé Bonpland a Butia Noblickii, espécie descrita apenas em 2012: de origem guarani, ambos são bem conhecidos e ainda de uso corrente na região.

Isoladamente, o termo "yatay" (yata'y, em guarani) se aplica, na Mesopotâmia argentina, Paraguai e oeste do Uruguai, a Butia yatay (Mart.) Becc. ${ }^{4}$, espécie que compõe extensos palmares, inconfundíveis, quando vistos de lon-

\footnotetext{
4 "Yatay, nome de palmeras de pequeña altura. En nuestro país: Butia yatay (Mart.) Becc. Palmera de poca altura pues no pasa de 10 metros, generalmente menos, estípite grueso cubierto durante mucho tiempo por la base de los pecíolos que en las palmas viejas caen dejando una cicatriz muy marcada ..." (GATTI, C. Enciclopedia Guarani-Castellano de Ciencias Naturales y conocimientos paraguayos. Asunción: Arte Nuevo Editores, 1985. p. 320-321).
} 
ge, por seus longos estípites e o tom cinzentoazulado das grandes folhas pinadas. $\mathrm{O}$ fato do termo se referir a uma palmeira em particular denota a importância que a população local lhe confere, seja pela contribuição fisionômica à paisagem, seja pelos frutos comestíveis e "muy perfumados", bem como pelas sementes, que se usam "pisadas en el mate contra calambres y palpitaciones"s.

O termo "poñi”, aposto a "yatay", informa que Aimé Bonpland reconhecia a proximidade da palmeira assim designada com o verdadeiro "yatay" (Butia yatay (Mart.) Becc.), mesmo a considerando espécie distinta (Figura 1).

A palavra "poñi", por sua vez, significa rasteira, prostrada, e se aplica a plantas cujo caule se $\operatorname{arrasta}^{6}$. Com o primeiro destes significados, o termo "poñi" também se usa, comumente, para distintas palmeiras acaules ou de estipe muito curto, tais como "Butia campicola (Barb. Rodr.) Noblick7, "Diplotemium ${ }^{8}$ e Butia poni".

Aimé Bonpland, que viveu por mais de nove anos em uma pequena localidade no interior do Paraguai, chegou a falar com fluência o guarani, visto ser esta a única língua utilizada pela maioria dos pacientes que lhe buscavam para atendimento médico naquele período. Por esse motivo, justamente, é que causa estranheza a atribuição desse nome comum a Butia Noblickii, espécie de caule conspícuo. A explicação mais provável, neste caso, é que, mesmo não sendo

5 GATTI, 1985. Op. cit., p. 321.

6 "Rastrero, postrado, dicese de las plantas cuyo tallo se arrastra" (GATTI, 1985. Op. cit., p. 249).

7 "Cocos campicola Barb. Rodr. Palmera enana que crece en grupos en los campos arenosos. Sus hojas se utilizan para fabricar escobas. En Corrientes (República Argentina) se llama asi a Butia yatay var. paraguayensis" (GATTI, 1985. Op. cit., p. 321).

8 Peralta \& Osuna, autores referidos na nota a seguir, referem-se, em verdade, a Diplothemium campestre Mart. (atual Allagoptera campestris (Mart.) Kuntze), uma espécie de palmeira anã que é nativa em savanas da província de Misiones, Paraguai e Brasil.

9 PERALTA, A.J.; OSUNA, T. Diccionario GuaraníEspañol y Español-Guaraní. Buenos Aires: Editorial Tupã, 1950. p. 164 planta rasteira, prostrada, o que o botânico francês visava a destacar, em suas referências ao "yatay poñi”, era o porte relativamente pequeno de seu estípite, comparado ao verdadeiro "yatay" (Butia yatay (Mart.) Becc.). A hipótese de Bonpland referir-se a uma palmeira verdadeiramente anã, tal como Butia paraguayensis (Barb. Rodr.) L.H. Bailey, B. poni (Hauman) Burret ou B. lallemantii Deble \& Marchiori, carece, inteiramente, de fundamentação, seja pelo texto do próprio autor, relativo às duas coletas ${ }^{10}$, seja pela inexistência de outras espécies do gênero Butia Becc. em todo o sudeste da província de Corrientes.

Outro ponto a ser comentado, prende-se ao fato do botânico também incluir "yatay poñi" entre as "Palmiers du Paraguay" (Figura 1). Não é de descartar-se, neste caso, a possibilidade de Bonpland referir-se, efetivamente, a Allagoptera campestris (Mart.) Kuntze (sin.: Diplothemium campestre Mart.) ou a uma das várias espécies anãs do gênero Butia Becc., nativas naquela república. Adúvida acima expressa tende a permanecer, tanto pela ausência de exsicatas em herbário, por ele coletadas, como pelo desconhecimento de um texto descritivo a respeito de seu "yatay poñi” paraguaio. Não seria de descartar-se, inclusive, uma eventual confusão, por parte do francês, de Butia Noblickii com Butia misionera Deble \& Marchiori, espécie recentemente descrita para a região das Missões, no estado do Rio Grande do $\mathrm{Sul}^{11}$, e nativa, igualmente, no nordeste da província de Corrientes, sul de Misiones e sudeste do Paraguai. Esta possibilidade respaldase no largo tempo transcorrido desde a saída definitiva de Bonpland do Paraguai e as duas co-

${ }^{10} \mathrm{~N}^{\circ}$ 2597, Sta. Ana de l'Uruguay (atual localidade de Bonpland, no município de Paso de los Libres), e $\mathrm{n}^{\circ}$ 2606, Restauración (atual cidade de Paso de los Libres), Nov. 1854 (MARCHIORI, 2015. Op. cit., p. 8-10).

${ }^{11}$ DEBLE, L.P.; MARCHIORI, J.N.C.; ALVES, F. da S.; OLIVEIRA-DEBLE, A.S. de. Survey on Butia (Becc.) Becc. (Arecaceae) from Rio Grande do Sul State (Brazil). Balduinia, Santa Maria, n. 30, 2011, p. 10-15. 


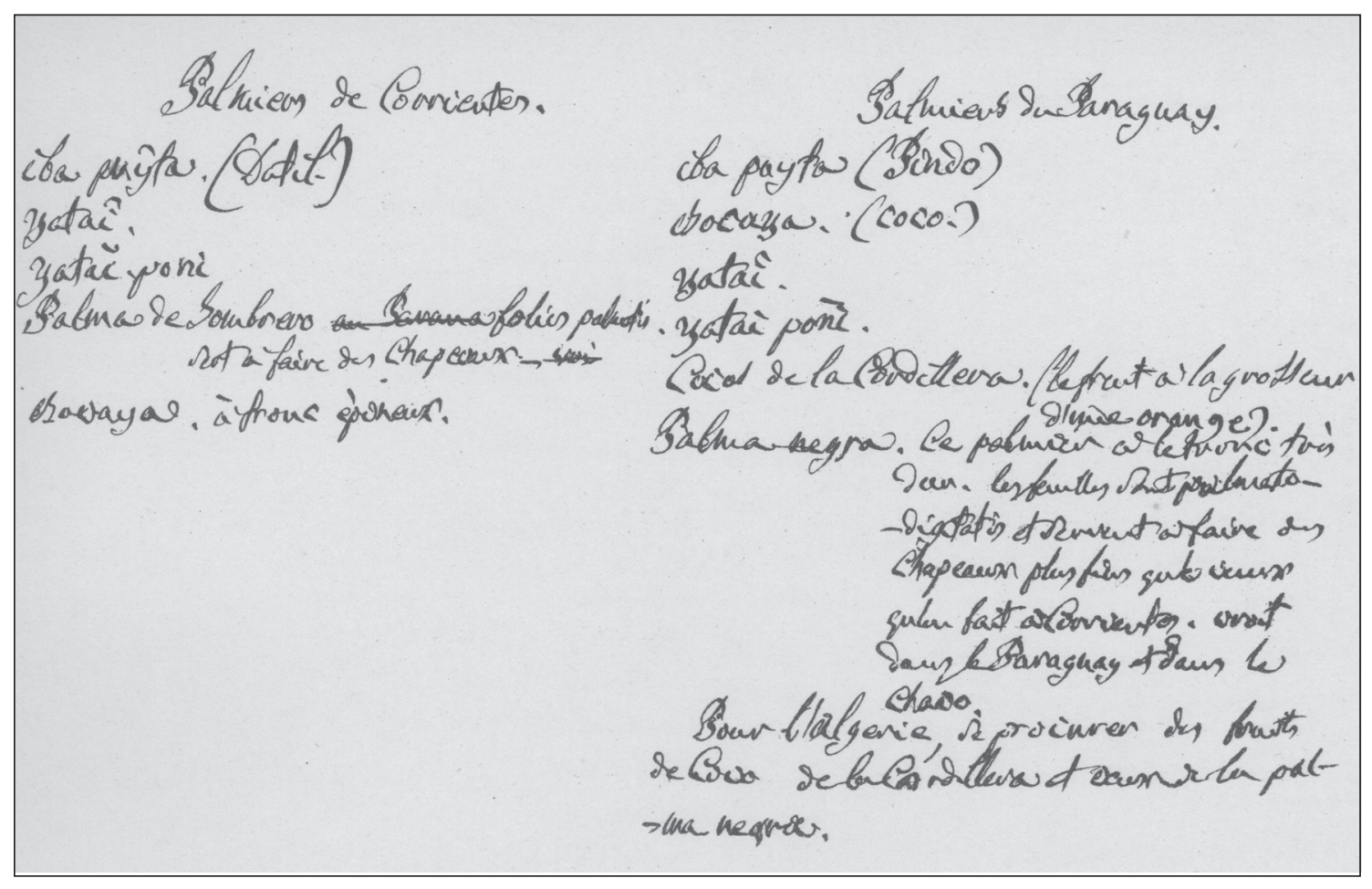

FIGURA 1 - Lista das palmeiras de Corrientes (Palmiers de Corrientes) e do Paraguai (Palmiers du Paraguai), constante em uma das páginas finais do Journal de Botanique de Aimé Bonpland, publicado em edição fac-similar sob o nome de Archives Inédites, no ano de 1924. Notar a inclusão do “yatay poñi” em ambas as colunas.

letas de "yatay poñi”, por ele realizadas em 1854 no sudeste da província de Corrientes.

\section{CONSIDERAÇÕES TAXONÔMICAS}

Utilizado por Aimé Bonpland para designar, provisoriamente, uma espécie de palmeira por ele coletada em 1854 na província de Corrientes, o termo "yatay poñi", por ser nome vulgar, tem valor puramente literário e histórico.

Na terminologia botânica, o epíteto "poñi", mediante latinização, foi proposto pelo professor e engenheiro agrônomo Lucien Leon Hauman-Merck ${ }^{12}$ (02-VII-1880 - 16-IX-1965),

12 Belga de nascimento, Hauman desenvolveu sua carreira profissional na Argentina, aonde chegou em 1904 para lecionar na recém criada "Facultad de Agronomía y Veterinaria" da Universidade de Buenos Aires. Além de destacado botânico, micólogo e briólogo, Hauman ganhou a posteridade ao emprestar seu nome ao Jardim Botânico da UBA. como epíteto específico de uma espécie de palmeira anã (Cocos poni Hauman), por ele descrita em 1919:

"Otra palmera enana característica de la misma sabana misionera y común al lado del Diplothemium: es el "Yatay poñi" de los habitantes de Misiones. Del punto de vista botánico, es parecidísima al Cocos yatay Mart., pero se diferencia de él por el hecho notable de florescer y fructificar sin formar tronco, mientras el "Yatay" no llega a ser fecundo antes de tener un estípite de cerca de 2 metros, como lo comprobé en los mismos campos de San Ignacio, donde también existe". ${ }^{13}$

13 “Outra palmeira anã característica da mesma savana missioneira e comum ao lado do Diplothemium: é o "Yatay poñi" dos habitantes de Misiones. Do ponto de vista botânico, é parecidíssima a Cocos yatay Mart., porém se diferencia dele pelo fato notável de florescer e 
A descrição original de Cocos poni foi ilustrada, pelo autor, com foto da planta inteira (Figura 2) e detalhes da inflorescência (Figura 3). Na primeira, vê-se que o hábito "rasteiro" de Cocos poni Hauman, resultante de um estípite muito curto, corresponde, com perfeição, ao epíteto específico recebido, permitindo distinguir essa espécie do "yatay poñi" de Aimé Bonpland (Butia Noblickii) apenas com base neste aspecto morfológico. Como visto no capítulo precedente, o que o botânico francês visava a destacar, no caso em foco, era o porte relativamente pequeno do caule de Butia Noblickii, espécie por ele chamada de "yatay poñi", comparado ao verdadeiro "yatay" (Butia yatay (Mart.) Becc.). Neste particular, o que chama atenção é que tanto a palmeira referida por Bonpland como a espécie de Hauman receberam um mesmo nome comum (yatay poñi), coincidência que, entretanto, não constitui raridade na nomenclatura vulgar.

A respeito do "yatay poñi" de Hauman, resta acrescentar que a espécie foi transferida ao gênero Butia Becc. em 1930, por Karl Ewald Maximilian Burret (1883-1964); a espécie, por conseguinte, passou a chamar-se Butia poni (Hauman) Burret, e o binômio Cocos poni Hauman acabou reduzido à sinonímia.

\section{CONCLUSÕES}

As considerações etimológicas e taxonômicas precedentes indicam as seguintes conclusões:

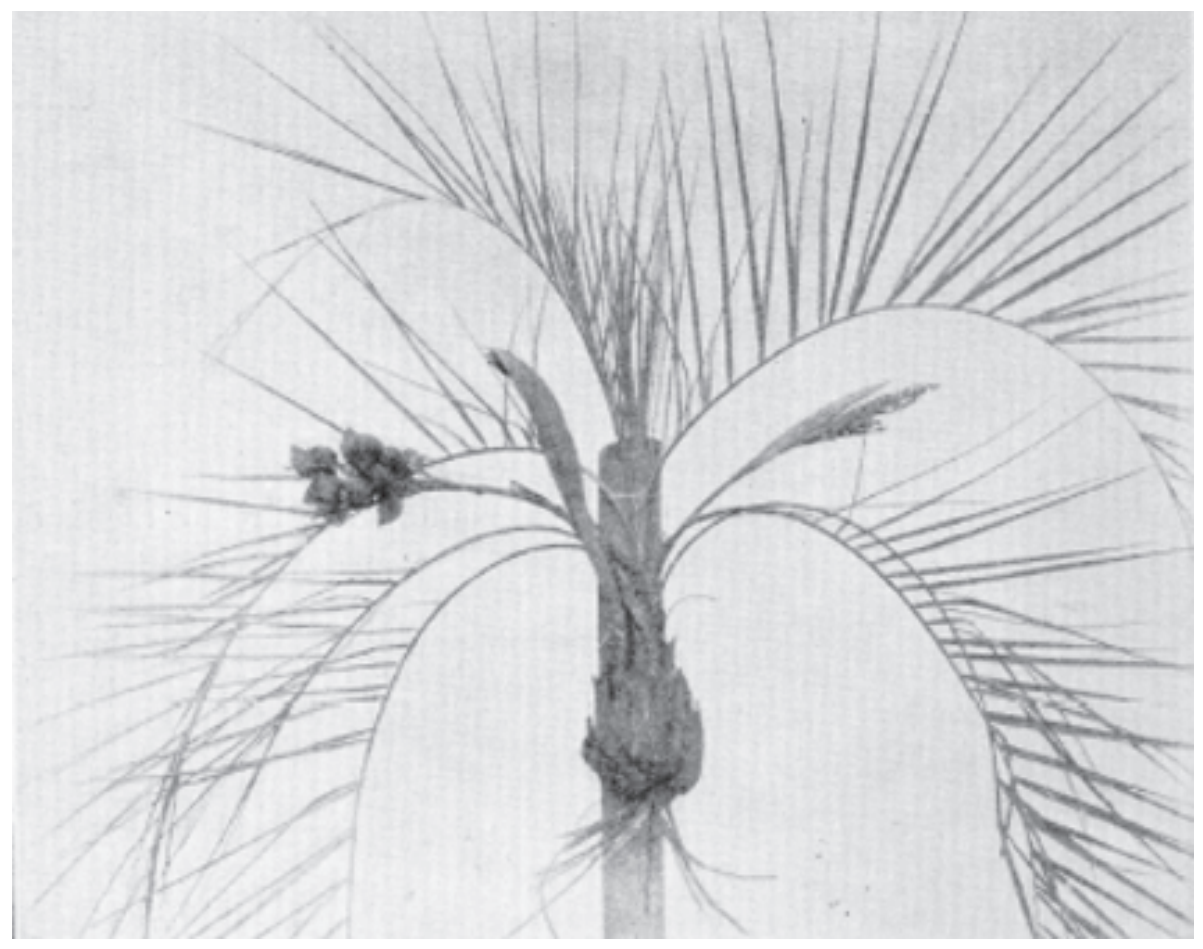

FIGURA 2 - Foto da planta inteira de Cocos poni Hauman (atual Butia poni (Hauman) Burret). Notar que se trata de uma palmeira anã, de estípite muito reduzido, ao contrário de Butia Noblickii Deble, Marchiori, F.S. Alves \& A.S. Oliveira. Fonte: Hauman, 1919. Op. cit., p. 604.

frutificar sem formar tronco, enquanto o "Yatay" não chega a ser fecundo antes de ter um estipe de cerca de 2 metros, como o comprovei nos mesmos campos de São Inácio, onde também existe" (Extraído, mediante tradução de: HAUMAN, L. Las palmeras de la Flora argentina. Physis, Buenos Aires, v. 4, 1919, p. 604). 